\title{
Book Review: Geographies of Race and Food: Fields, Bodies, Markets
}

\section{ISE blogs.Ise.ac.uk/lsereviewofbooks/2013/11/07/book-review-geographies-of-race-and-food-fields- bodies-markets/}

\section{Blog Admin}

What difference does race make in the fields where food is grown, the places it is sold and the manner in which it is eaten? How do we understand farming, eating, and hunger better by paying attention to race? This collection argues there is an unacknowledged racial dimension to the production and consumption of food under globalization. As a contribution to the study of both food and race, it certainly achieves its goal of broadening both fields, bringing an antiracist perspective to food scholarship, and deepening our understanding of how race is constituted in ways which are not always obvious, writes Eona Bell.

\section{Geographies of Race and Food: Fields, Bodies, Markets. Rachel Slocum and Arun Saldanha. Ashgate. October 2013.}

Find this book:

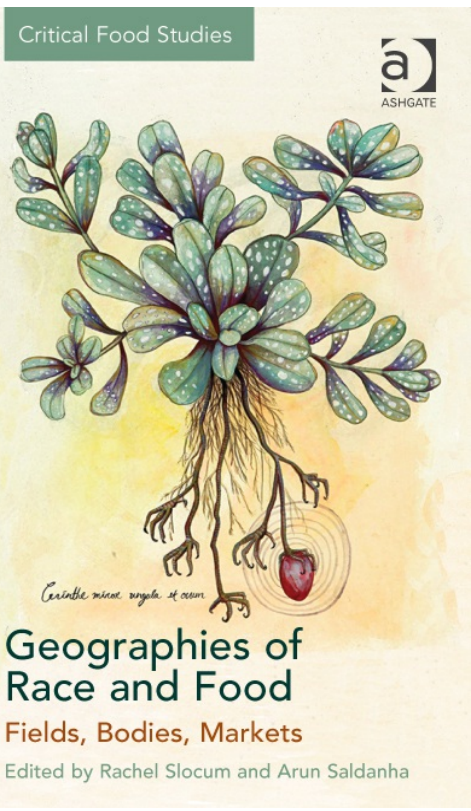

kindle edition

amazon

It is well recognised that differences in social class and economic status contribute to social inequality with regard to food, but the importance of race in food-related power relations has not generally been brought to the fore. Yet in our post-colonial globalized world, racism is endemic in the production, distribution, and consumption of food, where 'certain populations of bodies are structurally recognized as less worthy of sustenance and luxury'.

This claim by the editors in their introduction to Geographies of Race and Food: Fields, Bodies, Markets has motivated a collection of essays which together draw attention to the issue of race as a salient element in food politics. Julie Guthman, who provides the foreword, and co-editor Rachel Slocum noticed how in the US context which they describe, new social movements connected with food, such as those pushing for localism in food supply, are dominated by white, relatively wealthy people. This excludes others within an agricultural economy which is already highly racialized in terms of both farm labour and access to food. There is an issue of social justice around food, and not only in the US. Co-editors Slocum and Arun Saldanha argue that not only does food 'get at the heart of what it means to be human,' but it is also central to the 'amaranthine question of "difference" under capitalism'.

This book argues strongly for the need for research to focus on race and bodies in relation to the production and consumption of food, but also that it is possible to 'rethink race at the physiological level without giving in to the essentialist stories of environmental determinists and old-fashioned racist psychologists.' This means that, while the authors take a predominantly anti-racist stance, they pay serious attention to the reality that in economic and social 
life, people do attach value to phenotype and thus mobilize race as a significant category. Slocum provides a thorough review of the literature on race and food - predominantly in geography but with reference to other disciplines - in an early chapter which in itself may serve as a useful starting point for anyone wishing to take up the challenge of pursuing future research in this area.

Differential access and allocation of food produces some of the huge inequalities and injustices in the present world. Thus the topics of race and food must be of interest and concern to activists and politicians as well as academic researchers. In bringing the two together, the authors make an important contribution to the growing interdisciplinary field of food studies, by advancing some of the many questions which arise from the exploration of a diverse range of subjects, including slavery, migration, climate change, food deserts, food safety, hunger and desire. The book is divided into three sections - entitled Fields, Bodies, and Markets - and opens with a strong introduction which opens up these three concepts theoretically and draws together some of the common threads between the fifteen subsequent chapters.

To pick out just one chapter from the Fields section, which contains chapters on ecology, labour and inequality, Judith Carney describes the control of food in American plantation societies. Many of the foods now celebrated in the culture of the US South - rice and peas, okra, palm oil and black-eyed beans to name just a few - were originally African, brought over by slaves to sustain them on the ships, and later cultivated on their food plots in the Americas. Already expert in tropical farming, African and Amerindian slave labourers played a crucial role in growing the food essential to the survival of early plantation societies. At the same time, Carney shows how access to food could be manipulated as a means of racist oppression, for example when slaves were obliged to cultivate their own food on private plots, but allowed little time or land in which to grow the staples they needed to survive.

Developing the idea of embodiment within a theoretical framework inspired by Jacques Lacan, in the chapter "Diet, Taste, Biopolitics" from the second section on Bodies, Nazanin Naraghi and Paul Kingsbury draw attention to the aesthetic and emotional aspect of eating, in relation to race, cultural identity and multiculturalism. Arguing that social constructionist arguments are insufficient to account for the power of racism and nationalism, they describe the elements of desire and enjoyment which inspire a specific subjectivity in people, such as in this case the IranianCanadians who participate in a very sensory and nostalgic way in the consumption of food at a cultural festival in Vancouver. When they display and eat symbolic foods during celebrations for the Persian festival of Nowruz, Iranian-Canadians enjoy an aesthetic experience which goes far beyond the simple attempts of the Canadian state to promote multiculturalism, or the modern Iranian state to impose its form of national identity. This chapter makes an 
interesting counter-argument to those who would favour political explanations for group identification, but it is not obvious how they are theorizing 'race' as opposed to ethnic or national identity which may be less phenotypically marked in this case.

The Markets section moves more globally to the food trade without neglecting its social aspects. Chapters by Aaron Bobrow-Strain and Mimi Sheller look at the trade in white bread and bananas respectively. Sheller's chapter offers some hope that food exchange - here the consumption of fair-trade bananas - may in fact break down some racialized boundaries between groups. Bobrow-Strain uncovers the history of industrial bread-making in the US in the twentieth century, showing how biopolitics has shaped the mechanics of bread production as manufacturers have responded to the wish of consumers to position themselves socially through the food they eat. Public anxiety about food purity and hygiene in general are convincingly shown to have influenced the marketing of white bread to (predominantly white) US housewives, but the argument that these were also connected to media debates about the racial purity of the US population is less strongly argued.

This is a well-produced volume, incorporating some fascinating illustrations and a good index. As a contribution to the study of both food and race, it certainly achieves its goal of broadening both fields, bringing an anti-racist perspective to food scholarship, and deepening our understanding of how race is constituted in ways which are not always obvious. While aimed at an academic readership, the rich empirical data in the chapters, and highly topical subject matter may also appeal to a non-specialist audience.

Eona Bell has a PhD in social anthropology and an MSc in cognitive anthropology from the LSE. Her doctoral thesis was about multiculturalism, learning and ethnic group formation in Edinburgh's Hong Kong Chinese community. Read more reviews by Eona. 